\title{
THE USE OF SAHRIS AS A STATE SPONSORED DIGITAL HERITAGE REPOSITORY AND MANAGEMENT SYSTEM IN SOUTH AFRICA
}

\author{
N. G. Wiltshire ${ }^{\text {a }}$ \\ a SAHRA, 111 Harrington Street, Cape Town, 8001 South Africa 1 - nwiltshire@sahra.org.za
}

KEY WORDS: heritage, gis, digitisation, creative commons, e-government, drupal, content management system

\begin{abstract}
:
SAHRA has developed versions 1 and 2 of the South African Heritage Resources Information System (SAHRIS - www.sahra.org.za) in 2012 and 2013. The system has been rolled out since May 2012 to the national and provincial heritage authorities in South Africa in line with the National Heritage Resources Act (Act 25 of 1999). SAHRIS was developed using Drupal and Geoserver, both of which are free open source software packages. The three core functions of SAHRIS include: an online application system for developments that is integrated with a commenting module for public participation; a national sites archive of heritage sites; and a comprehensive collections management system for objects. With Geoserver, Openlayers and GMAP, users are provided with an online GIS platform that is integrated with most of the content types on SAHRIS.

More than 21000 sites have already been migrated into SAHRIS along with over 4300 objects. The media and reports archive has already grown to 500 gigabytes, data storage is offered free of charge and so far 96 Terabytes of replicated storage have been installed. The distribution and dissemination of this content is facilitated by the adoption of The Creative Commons South Africa license.

Lessons learnt from previous attempts to develop SAHRIS are covered briefly in light of the opportunities that have been opened up by the relatively recent maturation of FOSS content management systems. The current uptake of SAHRIS and the solutions to the challenges faced thus far are discussed before concluding with the implications for E-governance in South Africa.
\end{abstract}

\section{INTRODUCTION}

\subsection{The Legislation}

In South Africa, the National Heritage Resources Act (NHRA), Act 25 of 1999, replaced the National Monuments Act of 1969 (Hall 2005). The NHRA therefore came into being nearly six years after the end of apartheid in 1994 and it typifies the ideas in 'New Public Management' of the 1990s (Dunleavy et al 2006). The NHRA setup a three-tiered system for heritage management in South Africa as opposed to the former singletiered system for national monuments administered by the National Monuments Council (NMC). The South African Heritage Resources Agency (SAHRA) replaced the NMC as the national heritage authority and was charged with managing national heritage sites or 'Grade I' sites. Provincial heritage resources authorities would manage 'Grade II' or provincial heritage sites after a process of devolution from SAHRA and local municipalities would be in turn be placed in charge of 'Grade III' heritage resources of local significance. The Grade III tier was further split into three sub-categories, with IIIa= high, IIIb=medium and IIIc=low local significance (Deacon \& Pistorius 1996).

After a few years passed in the early 2000s, provincial heritage resources authorities (PHRAs) were established in all nine of South Africa's provinces, mainly staffed and located in the provincial offices of the Department of Arts and Culture. The only exception to this was the PHRA in KwaZulu-Natal, Amafa, which was established before SAHRA in 1997 under the KwaZulu-Natal Heritage Act (KZNHA). The KZNHA is very similar to the NHRA and in practice is implemented in exactly the same way as the NHRA. In fact, the KZNHA refers back to the NHRA where it does not deal with certain issues such as Section 38 of the NHRA.
There are currently 226 local municipalities in South Africa. In order for the full devolution process to be completed, the NHRA requires that 236 heritage authorities are established and functioning in South Africa. The stark reality is that in 2013 only two PHRAs are fully functional in the Western Cape and KwaZulu-Natal while others are either completely understaffed, under-trained or lacking the staff contingent to deal in all aspects of the NHRA. For instance, PHRA-Gauteng has a number of staff serving built environment applications but it has not hired an archaeologist and a committee structure to deal with matters pertaining to Section 35 of the NHRA. This has severely hampered their input on Section 38 applications which deal with most developments affecting their province as they cannot easily assess the applications in an integrated fashion.

Only one local municipality, the City of Cape Town Metropolitan Municipality, has applied to their PHRA, Heritage Western Cape, for powers over Grade III heritage resources. Negotiations have been ongoing for a number of years to finalise this process but it has yet to be concluded.

The South African Heritage Resources Information System (SAHRIS) was recently developed to address many of these challenges and its successful implementation will rely heavily on the capacity and political will of the various heritage authorities across the country.

\subsection{Development History of SAHRIS}

At SAHRA, a number of project managers were tasked to steer the development of the system and two main phases passed without fully achieving the ambitious aims of the project. In the mid 2000s, the groundwork for SAHRIS (formerly known as NHRIS or National Heritage Resources Information System) went through exhaustive public participation and data coding standards were drawn up (SAHRA 2005, 2006, 2007). A pilot project using Microsoft Access was initiated to digitally audit 
the heritage objects kept at six institutions as a proof of concept for phase two. Subsequently SAHRA took a decision to adopt the use of Free Open Source Software (FOSS) unless only proprietary solutions were available.

Fortunately, since the mid 2000s, the FOSS market has rapidly come of age in the area of Content Management Systems (CMSs). SAHRIS was developed using Drupal which has the largest base of developers and users worldwide who regularly contribute code and documentation to the Drupal Community. It is also one of the most difficult CMSs to learn as the number of features, options and customisability are much higher than other CMSs tailored to more general features required by end-users. For SAHRIS, the need for an integrated Geographical Information System (GIS) and various other key foundations of the system meant that Drupal was one of the only options that could realistically be considered as it had the functionality, support and open source code necessary to develop SAHRIS.

In just over three months, from the end of January to April 2012, Version 1 of SAHRIS was developed, and the first live data was entered by users at SAHRA in May 2012.

\section{WHAT IS SAHRIS?}

\subsection{An Integrated Heritage Management System}

The opening statement of the NHRA announced that the purpose of the NHRA was to:

"introduce an integrated and interactive system for the management of the national heritage resources; to promote good government at all levels, and empower civil society to nurture and conserve their heritage resources so that they may be bequeathed to future generations;"

SAHRIS is, first and foremost, a digital heritage management system which integrates the process of recording moveable (objects) and immoveable (sites) heritage resources with the management thereof. The idea of the 'national estate, owned by all of South Africa's people, was introduced by the NHRA and the management of it was accorded to SAHRA in terms of Section 39 of the NHRA.

The development for SAHRIS in 2012 was heavily focussed on embedding the system into the workflow of its users. This eliminated duplication caused by disconnected databases and paper-based processes and has led to rapid information accumulation. The databases of the National Inventory, Maritime \& Underwater Archaeology, Burial Grounds \& Graves, Archaeology, Palaeontology and Meteorites and Heritage Objects Units were consolidated and inventorised in SAHRIS in one integrated platform.

Applications for development projects triggering mining, environmental and heritage legislation are being submitted online as part of the self-service workflows introduced on SAHRIS. Importantly, all of these applications are being mapped on SAHRIS through user-friendly GIS tools that have been made available and users are therefore able to locate their cases spatially in ways they could never have imagined before. More than 5000 archived impact assessments and research projects dating back to the 1980s were imported into SAHRIS (Leslie \& Walker 2009) so that current and historical cumulative impact assessments could be done for the first time.
The GIS layers produced on SAHRIS enable the users to overlay their sites and applications over a multitude of other pertinent layers. This has already reduced the duplication of applications resulting from minor reference errors. The GIS data also removes the cumbersome administration of files when name or boundary changes to municipalities and districts occur as the coordinates remain constant through time.

SAHRIS's online permit application system is also being used extensively to manage cases affecting identified heritage sites, buildings older than 60 years or heritage objects which are destined for export (amongst many other forms of permit application types). Each site or object is linked to a case and permit history and applicants are required to update inaccurate or incorrect information on SAHRIS.

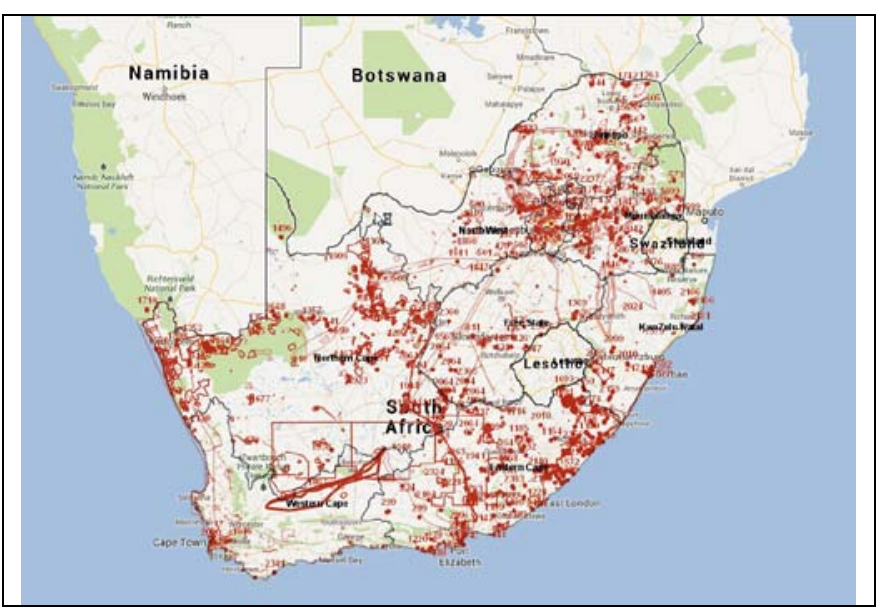

Figure 1. View of developments mapped on SAHRIS dating back to the 1980 s.

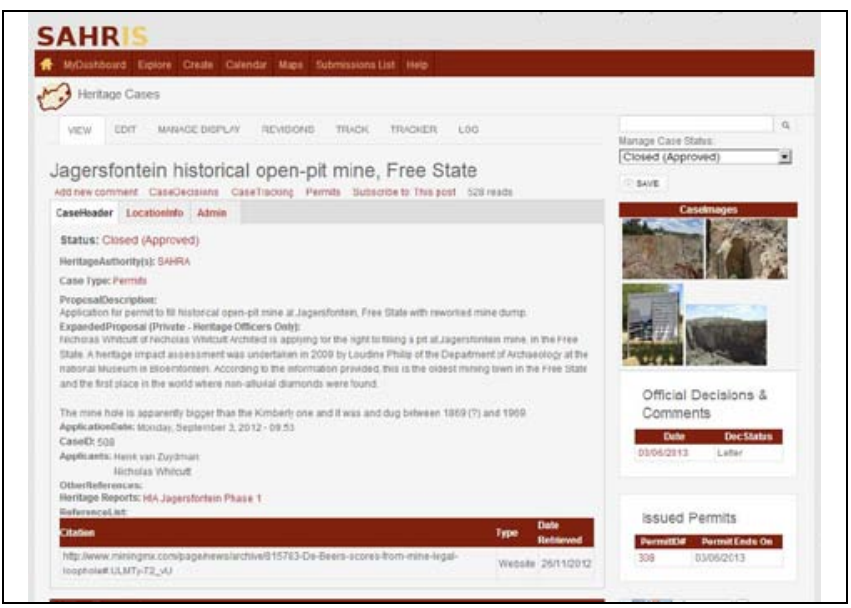

Figure 2. View of a development application on SAHRIS impacting an historical mine.

In March 2013, SAHRA announced that they would no longer receive paper-based or non-digital applications in order to ensure that the incoming documentation was henceforth archived electronically. This has already greatly reduced the workload on the staff employed in the Registry Unit who are currently digitising more than 2.5 million pages of older records predating SAHRIS to the early $20^{\text {th }}$ century. These digitised files will, in time, be linked and organised into the same structure as the current data in SAHRIS. 
SAHRIS also simplifies the public participation process required in Section 10 of the NHRA and in terms of other legislation involving Section 38(8) of the NHRA. Any member of the public can register a free account and can post their comments about applications within minutes of registration. This online commenting system is also being used by members of the various committees serving the heritage authorities so that decisions can be made online without the need to convene a physical meeting. This has greatly improved the speed with which applications can be decided and has simultaneously broadened free and transparent access to the planning process affecting citizens of South Africa.

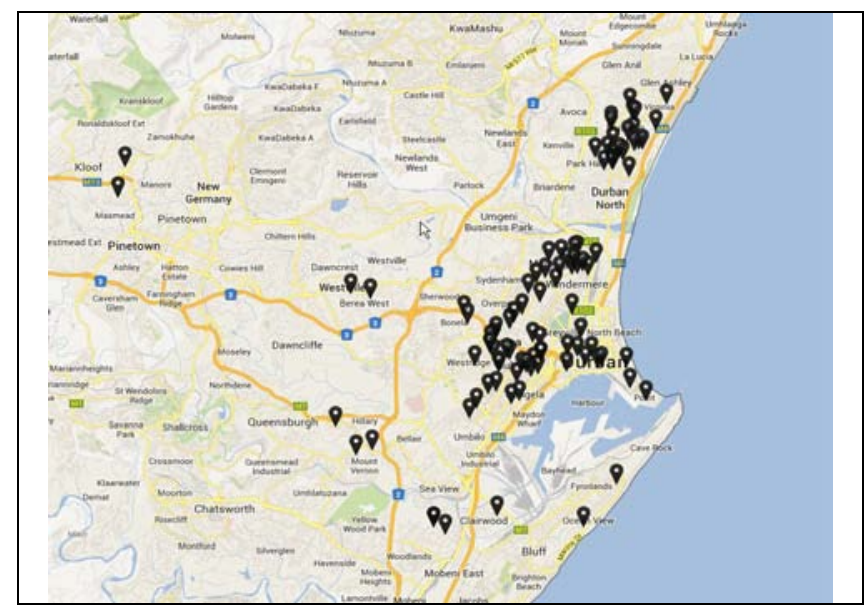

Figure 3. View of sites involving permit applications in KwaZulu-Natal.

\subsection{A National Heritage Sites Repository}

SAHRIS has restored the national repository for archaeological surveys which was disbanded in 1962 (Deacon 1993). In 2012, two major research archives of archaeological sites were migrated into SAHRIS from the Department of Archaeology at the University of Cape Town (5400) and the KwaZulu-Natal Museum (6000). These records were added after SAHRA's archives already mentioned. Amafa, the provincial heritage authority in KwaZulu-Natal, also donated more than 3000 sites from their heritage register of sites having local heritage significance. This brought the total number of sites to over 21000 in SAHRIS by March 2013.

In July 2013, SAHRA will be making the site recording system mandatory for all impact assessors submitting heritage impact assessments to the various heritage authorities in South Africa as a requirement of Section 39. This will mean that all sites identified during surveys for developments will be properly recorded in a standardised way on SAHRIS in addition to the heavily summarised versions of these recordings contained in the reports submitted by the impact assessors. This holds great potential for research as the traditional separation between commercial and research data is being eroded.

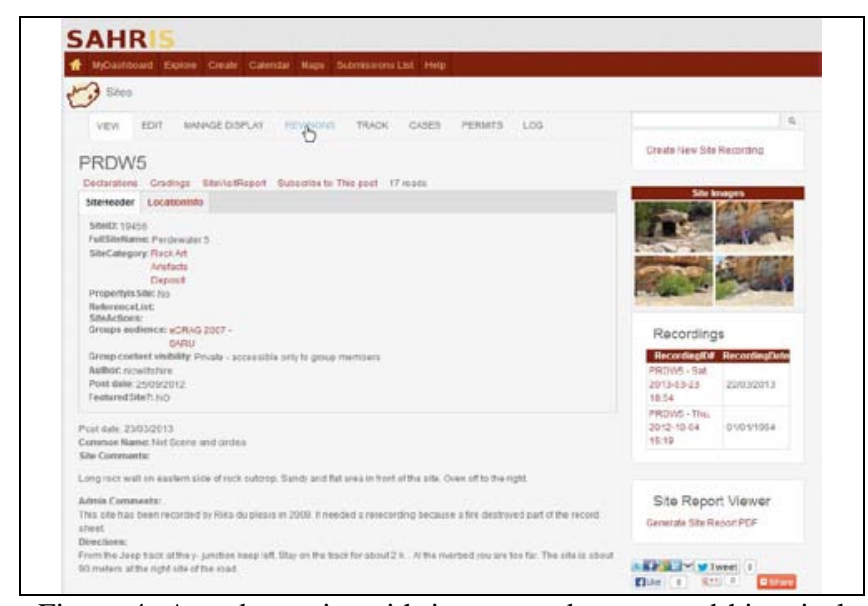

Figure 4. A rock art site with images and recent and historical site recordings.

In anticipation of the mandatory recording programme, two Network Attached Storage Servers each holding arrays of 48 Terabytes of storage were installed in data centres in Cape Town and Johannesburg. The users are able to upload very large amounts of data with automatic replication in 'the cloud'. The consequences for this will become more and more important as the years go by as practitioners and researchers are freed of the burden of having to manage their records at no cost to themselves. The total storage can easily be increased as the storage model is scalable and cheap.

There is still some way to go to correct the spatial information of the older archives of declared sites and shipwrecks, but most of the spatial information for the other sites archives are very accurately mapped (Jakavula 1999; Wiltshire 2005, 2011). An online competition run by the Wikimedia Foundation called 'Wiki Loves Monuments' was held in September 2012 for the first time in South Africa and it produced around 1800 photographs and updated the information for some of the sites on SAHRIS.

Over 500 Gigabytes of site-related imagery has already been uploaded to SAHRIS through the migration of data mentioned. In the early months of developing SAHRIS we had to choose a suitable licensing system for the content to ensure that it was disseminated legally and as openly as possible. In South Africa, the legislation contained in the Promotion of Access to Information Act (Act 2000) and Section 31 of the National Environmental Management Act (Act of 1999) guarantee public access to records and place South Africa on par with most democracies around the world in terms of transparency.

These laws do not apply to the research data donated to SAHRIS as public applications have not necessarily been invoked on most of the sites recorded during research surveys. We therefore chose to license all of the content on SAHRIS using a 'share and share alike' license called the Creative Commons South Africa (CCBYSA) license. This license allows users to freely share information they find on SAHRIS as long as they cite the author, do not sell the data, and, in turn, license their works derived from content on SAHRIS in terms of CCBYSA. The images available on SAHRIS are served online at a resolution of $800 \times 600$ pixels while the originating authors are able to download the full resolution versions of images they uploaded to the system. 
In addition to the mapping and recording of site locations, tools for survey layers have been included on SAHRIS to record the trackpaths and areas covered. These tracks are enclosed in polygons and are very useful for archaeologists establishing site densities. This data can in turn be used for more intelligent predictive modelling of unsurveyed areas in future. For palaeontologists, SAHRIS has a growing fossil sensitivity content type which will hopefully be linked spatially to the geological formations described in the sensitivity reports.

\subsection{A National Collections Management System}

The third core component of SAHRIS is the collections management suite of features. There are over 400 museums registered with the South African Museums Association (SAMA 2013) and a number of unregistered private museums in South Africa may well bring the total number of museums to 1000. The financial resources available to museums in South Africa have traditionally been low and numbers of visitors pale in comparison to their counterparts in North America or Europe. South African curators therefore tend to be a hardened bunch of 'do-it-yourself' professionals who have kept the

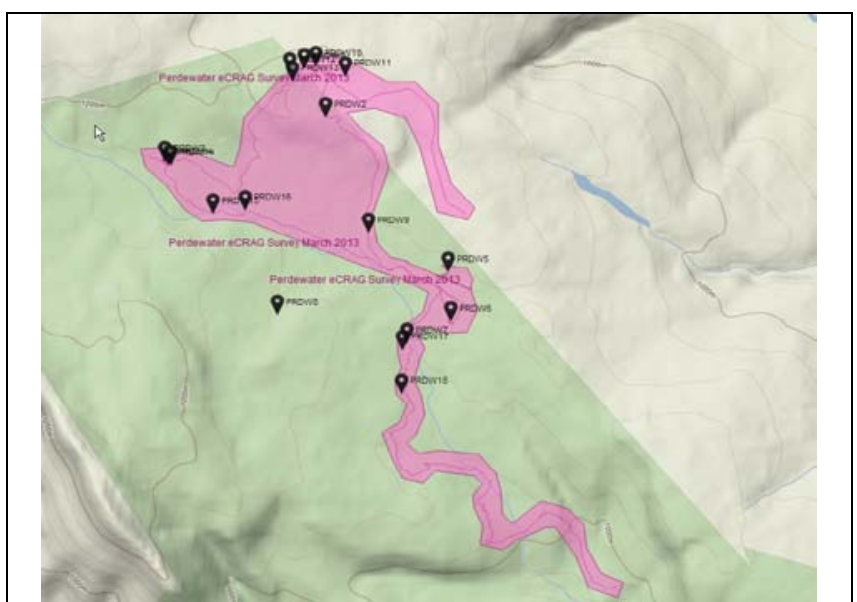

Figure 5. Map of sites (archival and recently surveyed) overlaid with the area surveyed.

industry alive despite the massive challenges they are facing.

SAHRIS addresses a series of needs in the museum industry in South Africa as it removes the entry fee to start small or large scale digital collection management at the various institutions. The curators no longer need to budget for software or storage solutions or even IT personnel to manage their digital data. Each institution using SAHRIS is given an 'Organic Group' within which access rights are determined by the curating team through a self-managed structure. Locations of objects and the tracking of movements are automatically set to private mode while the object descriptions, histories and photographic material are generally made available to the public unless exceptional circumstances require that even these records are hidden from view.

The NAS Servers allow for millions of images, reports or other media files to be uploaded to the objects. The Robert Chenhall classification system (Bourcier et al 2010) was chosen as a base from which to start the national set of terms describing the objects and various expert contributors are being trained to moderate the additions of new terms to the taxonomies on SAHRIS.
The commenting module is being applied to objects to initiate discussions and cross-institutional collaboration for a variety of reasons such as research, conservation of endangered objects and administration. For heritage managers working directly with heritage objects, the full permitting system is integrated with the objects in the same way as the sites described previously so that legal exports and conservation treatments can be tracked in a public space on the web. Objects are also declared as national heritage objects from time to time and this process is clearly defined on SAHRIS.

Another advantage of the new system is that it allows for intermuseum transfers of objects without the need for paperwork and duplication. Objects can easily be moved on SAHRIS from one location to another and the information naturally travels with the objects. Before SAHRIS, it was extremely difficult to track exhibitions and the responsible persons for looking after the objects taken out on loans. This is now accomplished quite easily.

Besides the standardisation and administrative tools offered to museums, SAHRIS is growing into a major research tool for people interested in objects. Students will be able to browse various collections online before they've even entered the museums in order to determine which items need detailed assessments as part of their research agendas. Curators working within various institutions are already drawing on information stored in other museums for objects which have similar provenances to improve their databases and the accuracy of their information.

For archaeologists, palaeontologists and other researchers excavating objects from site related contexts, SAHRIS offers integration between these records too. The excavations can be virtually classified and recorded long before the material even arrives at the door of the curating institution - simplifying the workload for all concerned while providing data entry options directly to the users creating the analyses in the first place.

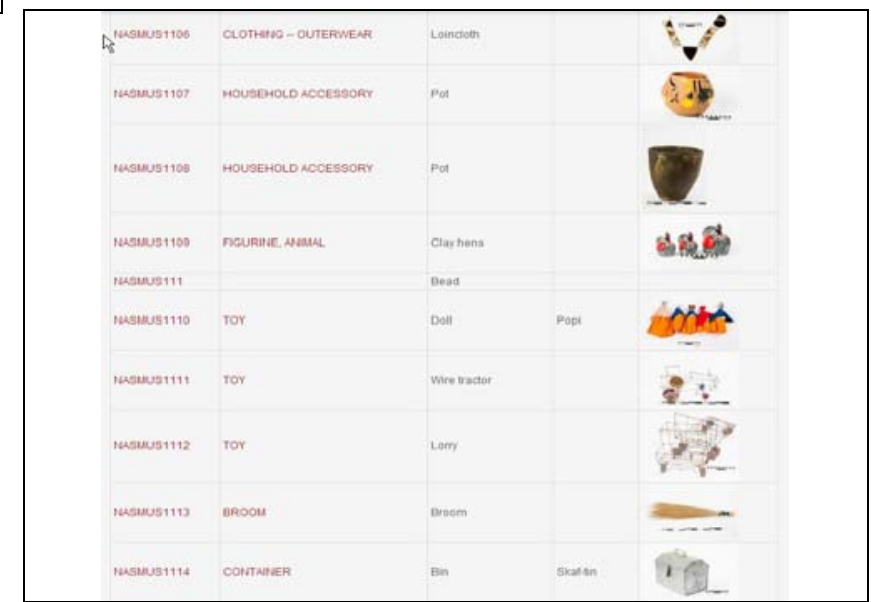

Figure 6. Object listing of some items captured on SAHRIS by museum curators.

\section{DISCUSSION \& CONCLUSION}

The rollout of SAHRIS has been welcomed in the heritage industry in South Africa, despite the delay of many years in producing the system. Over 1300 users (as at April 10, 2013) have registered accounts on SAHRIS and the daily visit count has moved from just over 200 per day to more than 500 a day. 
The number of pages viewed has grown from 6000 per month to 60000 and 17 workshops have been held around the country to promote the system and train the primary users of SAHRIS since October 2012.

The focus on PHRAs and their applicants for Version 1 has left SAHRIS with low penetration into the museum industry thus far. This pattern has gradually shifted as more and more objects are being promoted online from the audits of heritage objects coordinated by SAHRA since 2005. The need for a coherent and well-supported team of SAHRIS content moderators and trainers was identified during the recent annual planning for the 2013-2014 financial year and an internship programme has been initiated to train unemployed youth on digitisation through SAHRIS. It is envisaged that these job creation opportunities will extend beyond the confines of SAHRA itself as commercial operators take on support and training roles. This will require an accreditation system for SAHRIS and the early planning around these initiatives has recently been initiated.

The relative success of the development and implementation of SAHRIS in such a short space of time has largely been made possible by the strategic decision to adopt FOSS. Development on Drupal meant that very little coding was required and this allowed the development team to place more emphasis on the structure of the content types and their alignment with the legislation, the migration of data, training and delivery of the service. The open source model adopted by SAHRA could definitely be replicated by other government departments in South Africa, especially in the spheres of conservation, environmental and mining management since SAHRIS already encompasses the bulk of the functions of these interrelated departments (Kaplan 1993; Deacon et al in press).

A disappointing service delivery indicator has been the poor uptake of the public commenting system on SAHRIS. At the time of writing this paper, only committee members and heritage officers have made use of the commenting system while members of the public seem largely unaware or uninterested in submitting comments. The reasons for this probably lie in the general lack of awareness about what heritage authorities do in South Africa and the fact that most of their energies have been drawn into processing permit applications and developments that affect a very small and affluent sector of the population.

In the Western Cape, a longer tradition of registered conservation bodies around heritage applications exists, but unfortunately this went hand in hand with the fact that the NMC, now SAHRA, had their head office based in Cape Town. These heritage conservation groups tend to be constituted by retired volunteers who grew accustomed to dealing only with colonial heritage which was placed on the top of the agenda of the former government. The switch to the requirements of the new legislation has not been easy and the transformation process remains highly undemocratic despite the opportunities enshrined in the legislation and the provision of SAHRIS.

SAHRA has attempted to improve the public engagement with SAHRIS through the various workshops held thus far and by running articles inviting comments on the home page of their website. The system was also promoted for two hours on the morning news on $18^{\text {th }}$ March 2013 by televising live interviews and articles about SAHRIS. Despite these measures the system is still largely used only by applicants and specialised impact assessors. However, once the devolution of heritage management functions is achieved at local level, the system will no doubt receive much more active public support.

The quality and accuracy of the data on SAHRIS is currently a major focus point at SAHRA now that the tools have been developed to input and moderate the information. For applications, the data undergoes a rigid sequence of moderation by heritage officers. For information pertaining to sites and objects, specialist research groups currently moderate the information themselves before finalising the content on SAHRIS. SAHRA would also like to organically receive uploaded content from non-experts and is currently shifting expert users of SAHRIS at SAHRA into content moderation roles to ensure an overarching level of data cleaning takes place.

On the international front, this paper serves to announce the arrival of a sophisticated tool for heritage custodians around the world. The platform is fairly generic and can be adapted to any language. Slight adjustments would have to be made to adapt the system to local laws in other countries (Canouts 1999) but we openly invite other interested administrators to engage with us about the possibilities of implementing the same tools in their countries. A fully functional distribution of SAHRIS will be made available for free download on the SAHRA website by December 2013.

\section{References:}

Bourcier, P., Rogers, R. \& Nomenclature Committee. 2010. Nomenclature 3.0 for Museum Cataloging: Robert G. Chenhall's System for Classifying Man-Made Objects. Lanham: Altamira Press

Canouts, V. 1999. The U.S. National Archaeological Database: points of access. In: Hansen, H.J. \& Quine, G. (eds) Our Fragile Heritage. Documenting the Past for the Future: 165174. Copenhagen: National Museum of Denmark.

Deacon, J. 1993. Archaeological sites as national monuments in South Africa: a review of sites declared since 1936. South African Historical Journal 29: 118-131.

Deacon, J. \& Pistorius, P. 1996. Introduction and historical background to the conservation of monuments and sites in South Africa. In: Deacon, J. (ed.) Monuments and Sites - South Africa: 1-8. Colombo: ICOMOS.

Deacon, J., Walker, S.J. \& Wiltshire, N.G. (in press). Conservation of South Africa's West Coast archaeological heritage. In: A. Jerardino, D. Braun \& A Malan (Eds.) The Archaeology of the West Coast of South Africa. Johannesburg: Wits University Press.

Dunleavy, P., Margetts, H., Bastow, S. \& Tinkler, J. (2006). New public management is dead. Long live digitalera governance. Journal of public administration research and theory, 16 (3). pp. 467-494.

Gates, B., Myhrvold, N. \& Rinearson, P. (1995). The road ahead. New York: Viking, pp. 91-95.

Hall, A. 2005. Initiating a review of national heritage legislation in the South African experience. In: Ndoro, W. \& Pwiti, G. (eds) Legal frameworks for the protection of immovable 
cultural heritage in Africa: 36-41. Rome: ICCROM Conservation Studies 5.

Jakavula, Z.V. 1999. Archaeological sensitivity model: A Cultural Resource Management Exercise. Unpublished MSc dissertation. Cape Town: University of Cape Town

Kaplan, J. 1993. The state of archaeological information in the coastal zone from the Orange River to Ponta do Ouro. Pretoria: Department of Environmental Affairs and Tourism.

Leslie, M. \& Walker, S.J. 2009. Archaeology and palaeontology report mapping project. Introduction to DVD Version 1.0. Cape Town: South African Heritage Resources Agency.

South African Heritage Resources Agency (SAHRA), 20052007. Annual Reports 2005, 2006 \& 2007 http://www.sahra.org.za/about/publications (10 April 2013)

South African Museums Association (SAMA). 2013. List of Museums registered with SAMA http://sama.za.net/Muselist/muse-list.html (10 April 2013)

Wiltshire, N.G. 2005. Digitising the Cedarberg Rock Art Records \& Handheld Recording. Unpublished BSc (Hons) thesis: University of Cape Town.

Wiltshire, N.G. 2011. Spatial Analysis of Archaeological Sites in the Western Cape using an Integrated Digital Archive. Unpublished MSc thesis: University of Cape Town. 